\title{
The Impact of Antithrombotic Regimens on Clinical Outcomes After Endovascular Intervention and Bypass Surgery for Infrapopliteal Artery Disease
}

\author{
Amol Gupta ${ }^{\mathrm{a}, ~ e}$, Michael S. Lee ${ }^{\mathrm{b}}$, Kush Gupta ${ }^{\mathrm{c}}$, \\ Vinod Kumar ${ }^{\text {a }}$, Sarath Reddy ${ }^{\mathrm{d}}$
}

\begin{abstract}
Endovascular intervention and bypass surgery are the main options of treatments for infrapopliteal artery disease. Although post-intervention treatment with antiplatelet (AP) and/or anticoagulant (AC) drugs has reduced morbidity and mortality rates from cardiovascular complications; the ideal antithrombotic treatment regimen is unknown. The aim of this review was to compare the efficacy and safety of various anticoagulation and/or AP therapy regimens in patients undergoing below-knee endovascular treatment for infrapopliteal artery disease. We reviewed published literature in PubMed and Google Scholar, and Cochrane, evaluating efficacy and safety outcomes after antithrombotic treatment following endovascular intervention or bypass surgery in patients with infrapopliteal artery disease. We extracted relevant efficacy and safety data with related statistics from each study. We found that AP treatment should be administered to patients receiving endovascular therapy or bypass. We did not find superior effects for dual AP treatment (DAPT) over mono-AP therapy (MAPT) for endovascular intervention or bypass surgery with venous graft, suggesting that MAPT suffices for these groups. Also, aspirin + clopidogrel was effective over aspirin alone for prosthetic, but not venous graft, albeit higher non-severe bleeding incidences, suggesting a potential benefit of this regime for below-knee prosthetic graft. AP + AC yielded superior results compared to AP following endovascular procedure and bypass surgery, suggesting the potential benefit of this regime in the absence of contraindications. More prospective studies with large number of patients are warranted to identify the best treatment for infrapopliteal artery diseases.
\end{abstract}

Keywords: Antiplatelet; Anticoagulant; Infrapopliteal artery disease; Peripheral artery disease; Endovascular intervention; Bypass surgery

Manuscript submitted August 25, 2019, accepted September 12, 2019

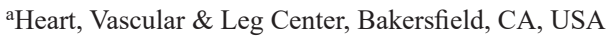

bDivision of Cardiology, UCLA Medical Center, Los Angeles, CA, USA

${ }^{\mathrm{c}}$ Kasturba Medical College, Mangalore, India

dThe Brooklyn Hospital Center, Brooklyn, NY, USA

${ }^{e}$ Corresponding Author: Amol Gupta, Heart, Vascular \& Leg Center, 5020

Commerce Drive, Bakersfield, CA 93309, USA. Email: amol@vippllc.com

doi: https://doi.org/10.14740/cr937

\section{Introduction}

Critical limb ischemia (CLI) represents the terminal stage of obstructive, atherosclerotic, peripheral arterial disease (PAD) $[1,2]$. Foot ulceration with tissue loss and gangrene are some of the manifestations of CLI, which may lead to major amputation if the affected arteries are not promptly revascularized [3]. Infrapopliteal arterial disease, alone or combined with other PAD, is the leading cause of CLI [4]. Despite advances in treatment of PAD, treatment of infrapopliteal arterial disease has several unique challenges that complicate the treatment compared to more proximal lower extremity disease [5, 6]. These include small vessel size, prevalence of diffuse multilevel and multivessel calcific disease, and fewer suitable target vessels for bypass, particularly in patients with diabetes or renal failure or both [7]. In addition, the rate of restenosis may reach levels up to $50 \%$ within 1 year following endovascular intervention for PAD [8-10]. Restenosis following endovascular intervention may be even higher and more challenging for patients with infrapopliteal artery diseases [11-13]. Similarly, graft occlusion rates following bypass surgery have been ranging from $15 \%$ for venous graft and $20 \%$ for prosthetic grafts, and this ratio dramatically increases for below-knee grafts $[14$, $15]$.

Although several pharmacologic and non-pharmacologic approaches have been evaluated to improve the results of endovascular intervention and bypass surgery, there is no consensus or verified therapeutic approach, which might be partly due to the complex heterogeneity of these patients $[16,17]$. In addition, the benefits of antithrombotic treatment for patients who undergo endovascular procedure for infrapopliteal diseases or lower extremity bypass to below-knee targets remain unclear. There are ample studies that reported the effects of antiplatelets (APs) and anticoagulants (ACs) on the clinical outcome following endovascular or bypass surgery for femoropopliteal artery segment and were reported in Cochrane system as reviewed by Vos et al [18]. However, similar studies for infrapopliteal artery are scarce in the literature. The recommendations of antithrombotic treatment following endovascular or surgical intervention for femoropopliteal artery diseases should not be expanded to infrapopliteal artery diseases. The importance of evaluating the effects of antithrombotic treatment following infrapopliteal artery intervention stems from the fact that 
infrapopliteal arteries have smaller diameter, thinner arterial muscular wall, and are more prone to lower pulsatile flow than femoropopliteal artery segment $[19,20]$. High patency rates in the infrapopliteal arteries or below-knee grafts are vital for maximized perfusion for tissue healing following intervention and the delivery of the drug following intervention plays a vital role in this process. The differences between the endovascular successes of drug-coated balloons were remarkable when used for femoropopliteal and infrapopliteal arteries where there was much success for the femoropopliteal arteries probably due to the aforementioned reasons and as reviewed [20]. With the expanded use of endovascular intervention and the probability of high restenosis rates in the infrapopliteal arteries than femoropopliteal arteries, it is essential to further investigate the effects of antithrombotic treatment following intervention for infrapopliteal artery. This is fundamental increase in drug delivery to this arterial segment consequently the outcome of the intervention.

The aim of this study was to gather and evaluate relevant literature for patients undergoing below-knee endovascular and bypass surgery treatment with regards to the efficacy and safety of various anticoagulation and AP therapy regimens. We also aimed to highlight current deficiency of information that interferes with sound treatment recommendations for this group of patients.

\section{Literature Search}

\section{Study design}

A standardized electronic literature search in English was conducted in PubMed and Google Scholar, and Cochrane for key terms including "clinical trial", "prospective", "retrospective", "angioplasty", "endovascular", "revascularization", "bypass", "antiplatelet", "anticoagulants", "platelet aggregation inhibition", "below the knee", "infrapopliteal", "peroneal", "crural", "tibial", "clinical trial", "prospective", "retrospective", "peripheral artery disease", and individual AP or AC drug name or category such as "aspirin", "clopidogrel", "cilostazol", and "warfarin".

\section{Selection criteria}

The studies included in this review met the following criteria: 1) Designed explicitly for infrapopliteal arteries, or we were able to extract the numbers of patients and outcomes for infrapopliteal arteries if the study contains other peripheral artery segment(s); 2) Studies that contain at least $70 \%$ of the injuries related to infrapopliteal arteries; 3) Designed to evaluate the effects of AP and/or AC on particular endpoints in a comparative manner (comparing two treatment groups); 4) APs and ACs were administered following endovascular intervention or bypass surgery (antithrombotic was not only applied to determine their effects during the surgery; 5) The study recorded significant outcomes such as patency, restenosis, reocclusion, target limb revascularization (TLR), limb salvage, major am- putation (above ankle area); major adverse cardiac events (MACEs) (any record of cardiovascular death, myocardial infarction, angina, stroke, hospitalization for heart failure), allcause mortality, and minor or major bleeding (major bleeding, intracranial hemorrhage, requiring blood transfusion, or any combination of these parameters); 6) Patients were followed up at least 3 months or 1 month following endovascular or bypass, respectively for endovascular and bypass; 7) Included at least around 10 cases/group; and 8) Study focus was either randomized clinical trial (RCT), prospective cohort, or retrospective (no collection of case control studies).

We reviewed the titles and abstracts of articles that we identified in the literature as potentially suitable for inclusion in the review. Then, we confirmed the eligibility of the manuscript for inclusion in this systematic review. We targeted the evaluation of four different antithrombotic therapeutic groups: mono-AP therapy (MAPT), dual-AP therapy (DAPT), AC, and $\mathrm{AP}+\mathrm{AC}$. We extracted the relevant data that evaluated effectiveness and safety of the therapeutic groups along with their relevant statistics from each study. Data were then categorized according to similarity of treatment regimen and approach (endovascular or bypass surgery). Our search resulted in six publications for endovascular intervention $(100 \%$ of the cases were for infrapopliteal arteries). With regard to studies involving bypass surgery, we found eight articles that matched the inclusion criteria (seven articles included $100 \%$ of the cases with grafts crossed the knee and one study with $70 \%$ of the grafts crossed the knee).

\section{Literature Review}

\section{The effects of AP and AC treatment following endovascu- lar interventions in infrapopliteal artery disease}

We found studies that evaluated MAPT, DAPT, and ACs, but there were no studies evaluating AP + AC. Table 1 illustrates the antithrombotic drug groups that were used in the studies included in the review along with their mechanism of action.

\section{Mono-AP and dual-AP therapy}

Table 2 shows the effects of MAPT and DAPT on many effectiveness-related parameters such as patency, restenosis, occlusion, TLR, major amputation, MACEs, and all-cause mortality, as well as bleeding, the safety-related parameter [21-23]. We found only one study that evaluated MAPT effect (lipoecraprost) compared to placebo that showed no superior effect of lipo-ecraprost over placebo for amputation [21]. DAPT treatment with aspirin + cilostazol did not show any significant effects over MAPT effects for restenosis, major amputation, MACE mortality [23]. However, the data from Soga et al [22] showed the value of the addition of cilostazol to the platelet treatment regime by improving restenosis, reocclusion and TLR parameters to the platelet treatment regime. Also, Lejay et al [24] showed the significance of the compliance of the patients with their described anti-platelet treatment schedule, 
Table 1. Drugs and Mechanism of Actions

\begin{tabular}{ll}
\hline Drugs & Mechanism of actions \\
\hline Antiplatelet & Thromboxane A2 inhibitors \\
Aspirin & Phosphodiesterase inhibitors \\
Cilostazol & P2Y12/ADP receptor inhibitors \\
Clopidogrel & Prostaglandin E1 analog \\
\hline Lipo-ecraprost & P2Y12/ADP receptor inhibitors \\
Ticagrelor & P2Y12/ADP receptor inhibitors \\
\hline Ticlopidine & PDE inhibitors \\
\hline Dipyridamole & Defibrinating agents \\
Anticoagulant & Inhibiting the synthesis factors II, VII, IX and X, as well as the regulatory factors protein C, protein S, and \\
\hline $\begin{array}{l}\text { Batroxobin } \\
\text { Warfarin }\end{array}$ & protein Z \\
\hline Heparin & Inactivating thrombin and factor Xa \\
\hline $\begin{array}{l}\text { Dabigatran } \\
\text { Rivaroxaban and apixaban }\end{array}$ & Inhibiting free factor Xa and factor Xa bound in the prothrombinase complex \\
\hline
\end{tabular}

PDE: phosphodiesterase; ADP: adenosine diphosphate.

which was particularly important for the patency of the arterial segment following endovascular procedure. There were no significant differences between the groups for the bleeding events for studies that reported this outcome [22, 23].

\section{Mono-AP and mono-AP plus AC therapy}

Table 2 presents the effectiveness of MAPT versus AP + AC and the safety (bleeding) differences between the two groups [21-26]. The two studies were by the same group although one study was explicitly performed to evaluate the treatment effects on below-knee arteries [25], while the other included data for both femoropopliteal and infrapopliteal arteries [26]. The results were consistent regarding the significant improvement of reocclusion rates in response to batroxobin plus aspirin over aspirin for the infrapopliteal arterial segments. Bleeding events were also comparable between the two groups.

\section{The effects of antithrombotic treatment following below- knee bypass surgery}

\section{Mono-AP and dual-AP therapy}

Table 3 shows the effectiveness and safety of MAPT and DAPT [27-34]. Ticlopidine showed significant superior effects over placebo for graft patency and amputation [27]. DAPT studies suggested significant improvement of patency in prosthetic grafts, but not in venous grafts when compared to notreatment group [29]. Consistently, patients treated with DAPT had significantly higher patency rates as well as amputation rate but only for prosthetic grafts when compared with MAPT
[28]. Bleeding incidences were significantly higher in DAPT group compared to MAPT, albeit the severe and fatal bleeding incidences were comparable between the two groups [28].

\section{Mono-AP and mono-AP plus AC therapy}

We found one study that compared the two groups [30]. AP + AC was significantly superior than MAPT for patency and limb salvage rates. Hematoma, but not other bleeding events, was significantly higher in AP $+\mathrm{AC}$.

\section{AC therapy}

Table 3 shows three studies [31-33] that evaluated the outcome of different therapeutic regime of ACs. Direct oral ACs were suggested to have similar outcomes to traditional heparinwarfarin treatment for polytetrafluoroethylene (PTFE) grafts [31]. Low molecular weight heparin (LMWH) was superior to dextran for MACEs [32] and to unfractionated heparin for graft patency following bypass surgery. Therapeutic warfarin (international randomized ratio (INR) $\geq 2.0$ ) was superior to subtherapeutic warfarin $(\mathrm{INR} \leq 1.9)$ for graft patency and survival, albeit bleeding was relatively greater in therapeutic group [34].

\section{Discussion}

AP treatment seems to be essential and routinely used in the post-operative treatment of endovascular and bypass groups. We did not find superior effects for DAPT over MAPT for endovascular intervention or bypass surgery with venous graft, 


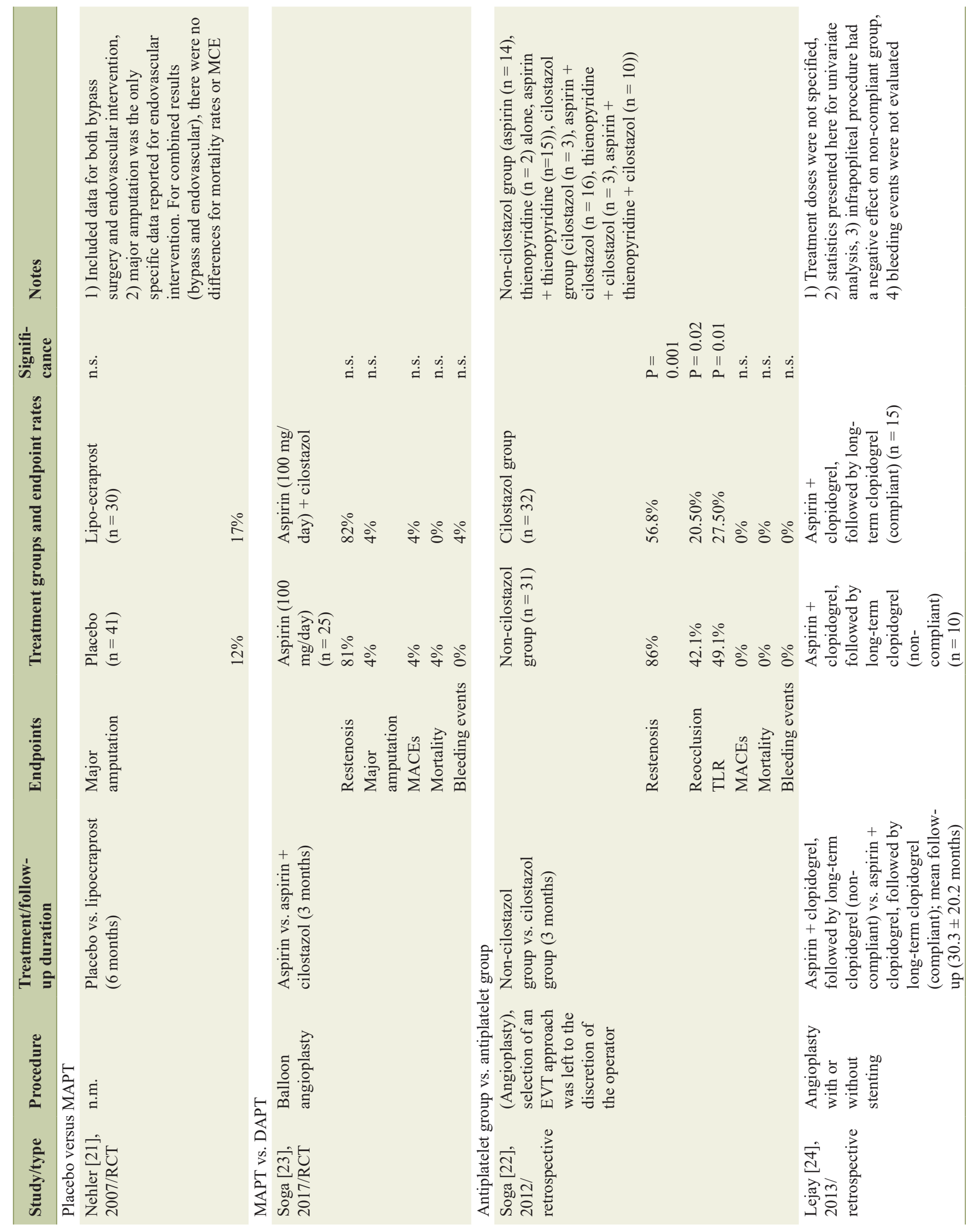




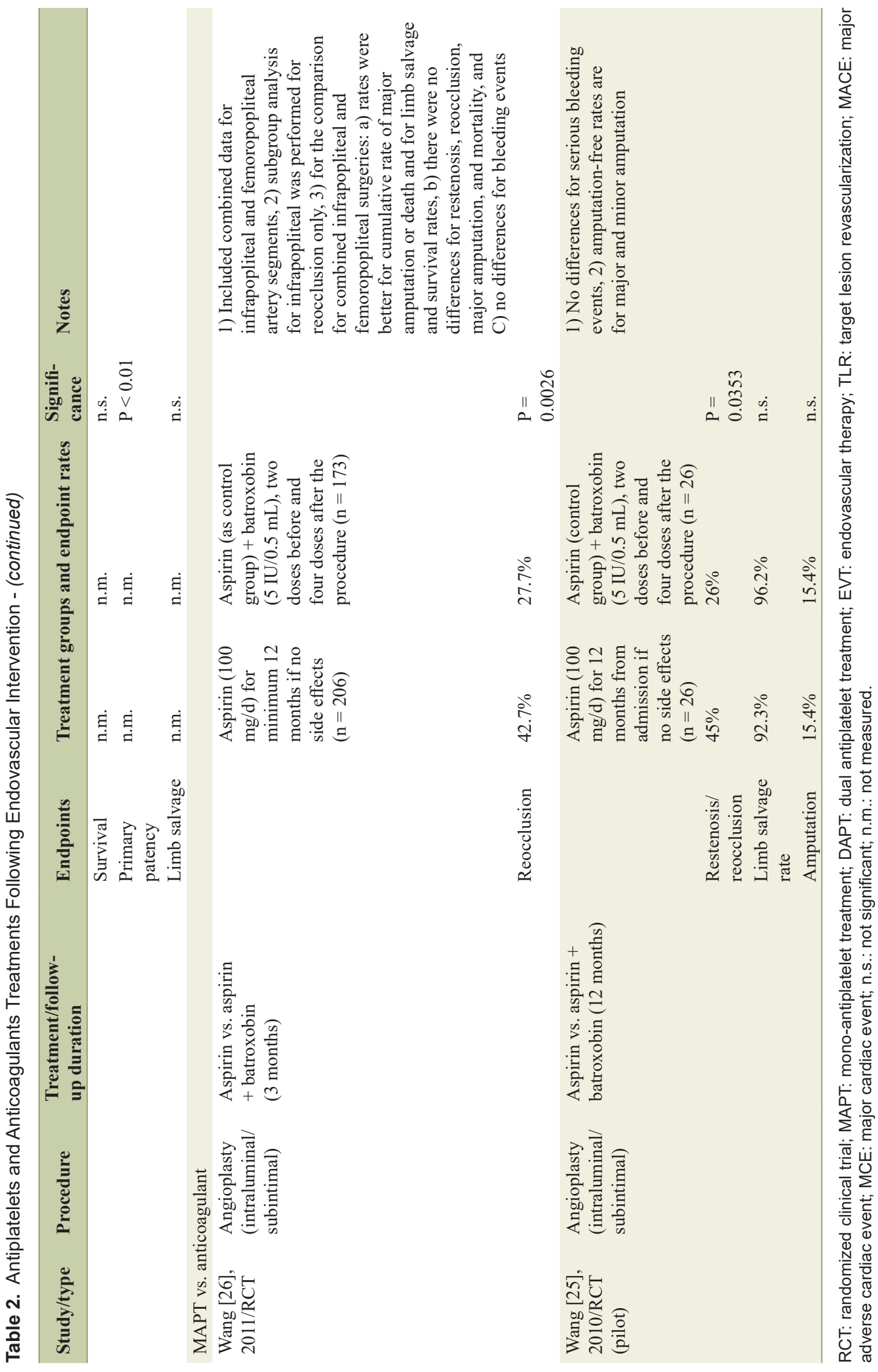




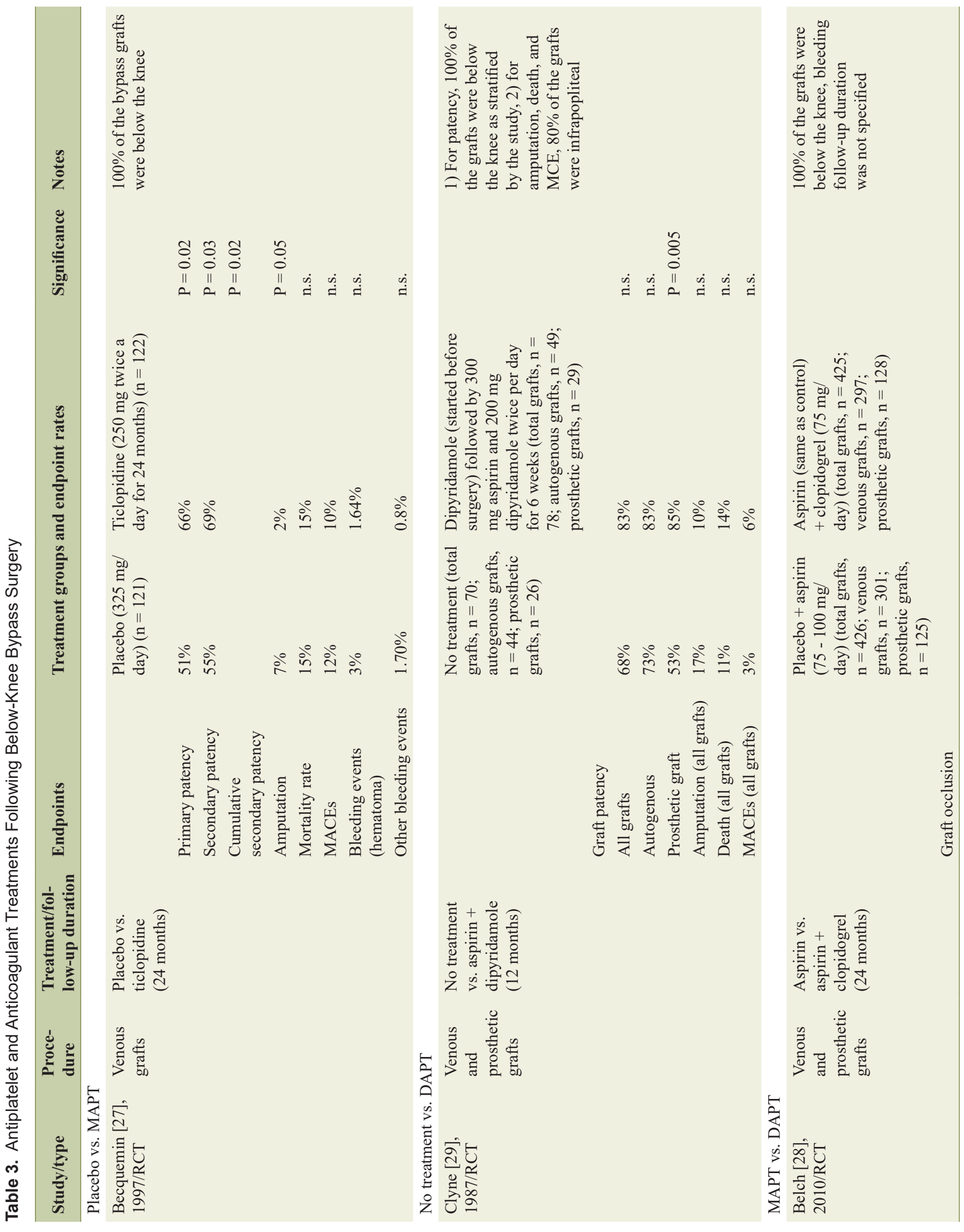




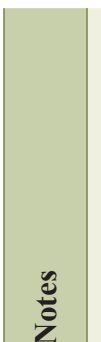

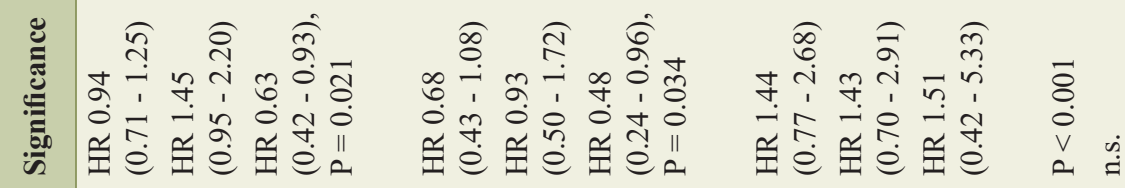

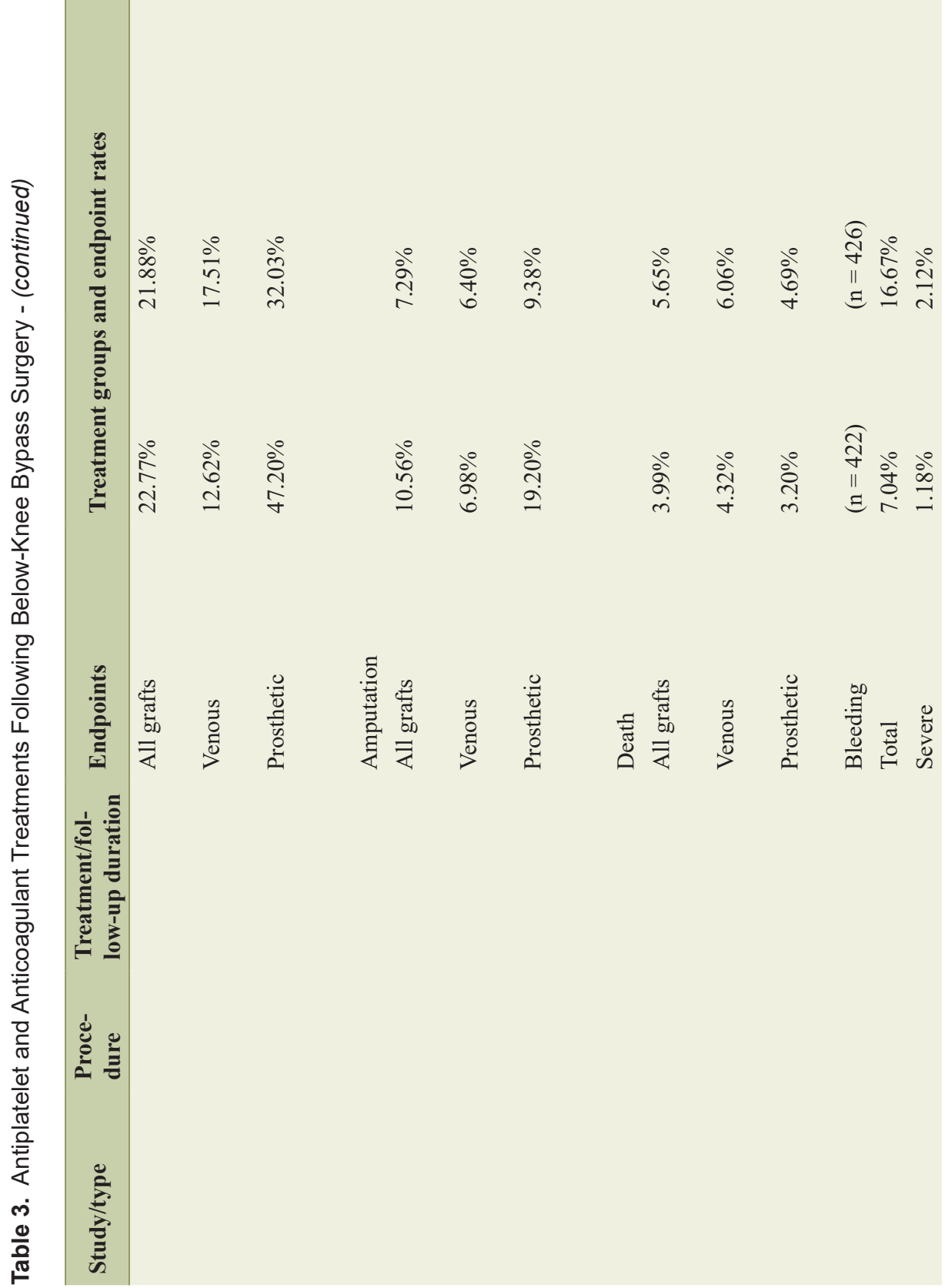

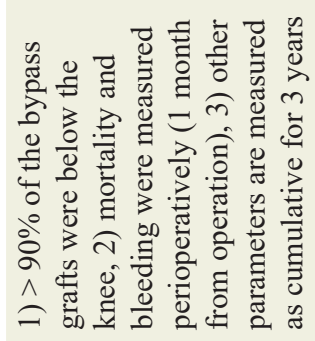

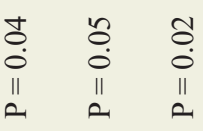

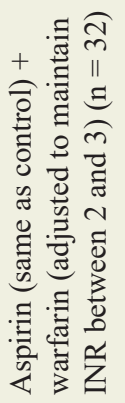

$\stackrel{+}{\stackrel{1}{i}} \frac{\circ}{\infty}$

bip

त्

氖

吾

ڤं

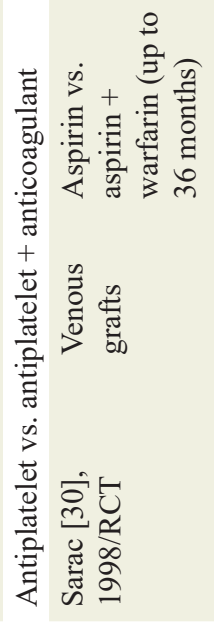




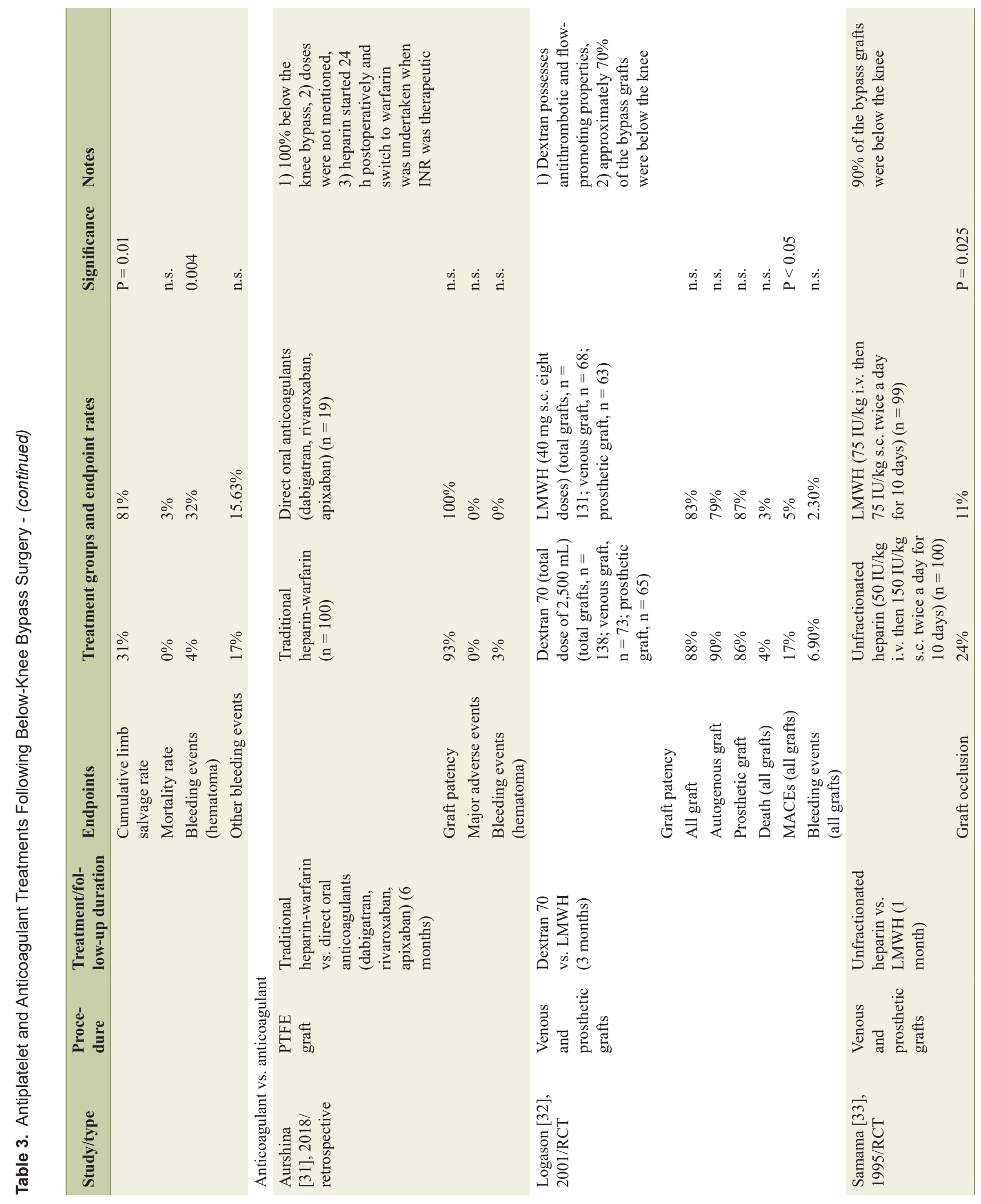




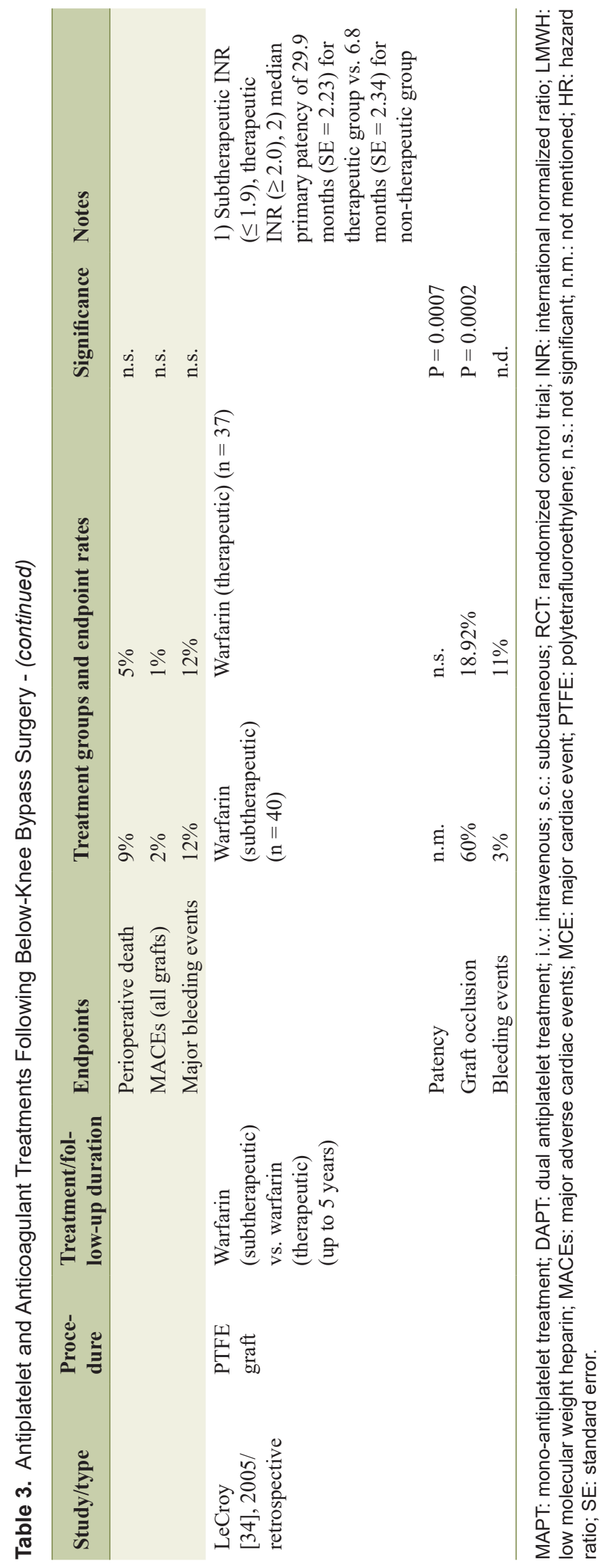

suggesting that MAPT suffices for these groups. However, DAPT in the form of aspirin + clopidogrel was effective over aspirin alone for prosthetic, but not venous graft. This superior effect was accompanied by the occurrence of non-severe and non-fatal albeit higher non-severe bleeding incidences, suggesting a potential benefit of this regime for below-knee prosthetic graft with required precaution. Also, AC or in combination with aspirin yielded superior results compared to AP alone following endovascular procedure, and bypass surgery for venous and prosthetic grafts, suggesting the benefit of this regime in the absence of contraindications.

\section{Antithrombotic treatment for endovascular intervention for infrapopliteal artery}

The benefits of post-endovascular intervention antithrombotic therapy for PAD in preventing cardiovascular complications are well known. Recommendations regarding the optimal regimen for patients with PAD including infrapopliteal artery diseases are variable and inconclusive [1, 2, 35, 36]. For instance, the European Society of Cardiology (ESC) guidelines recommend MAPT (aspirin) for angioplasty (class I recommendations) $[36,37]$. However, The American College of Chest Physicians advises the use of MAPT (aspirin or clopidogrel) following angioplasty (grade 1A) [37, 38], while The Society for Vascular Surgery recommends a minimum of 30 days of use of DAPT (aspirin and clopidogrel) following infrainguinal endovascular intervention (grade 2B) [35, 37].

Herein, in retrospective studies, cilostazol group has been reported to decrease the incidence of in-stent restenosis compared to non-cilostazol group in both infrapopliteal and femoropopliteal segments $[22,39]$. In contrast, RCT showed that while cilostazol plus aspirin were superior to aspirin alone following endovascular intervention for femoropopliteal artery [17], this effect disappeared for infrapopliteal artery [23]. The differences of cilostazol effects following endovascular intervention in retrospective study for infrapopliteal artery [22] and RCT [40] may be due to different treatment protocols, patient demographics, and the nature of the studies. Also, the differences for the cilostazol + aspirin effects on both femoropopliteal and infrapopliteal segments in RCT studies [17, 23] underscore the importance of evaluating antithrombotic treatments according to the injured arterial segment and that the treatment guidelines should not be generalized.

A review by Olinic et al suggested the treatment with aspirin plus clopidogrel for at least 1 month post-stent implantation, or with aspirin plus ticagrelor for PAD patients with a history of myocardial infarction [41]. Lejay et al [24] found that compliant group for the treatment with aspirin and clopidogrel had better patency than corresponding non-compliant group. This study underscores the importance of reinforcing medical follow-up following endovascular intervention [24]. However, studies comparing the combined effects of aspirin and clopidogrel with MAPT for infrapopliteal artery segments are needed.

Two studies $[25,26]$ showed that the combined treatment by $\mathrm{AP}$ and $\mathrm{AC}$ had significantly higher patency rates than $\mathrm{AP}$ 
alone for infrapopliteal artery diseases. Interestingly, in one of the two studies, there were no significant differences for patency between the two treatment groups when the data were evaluated for PAD, but significant differences were monitored when data was stratified for infrapopliteal artery [26], further underscoring the importance of specifying treatments according to the injured artery segment. The Cardiovascular Outcomes for People Using Anticoagulation Strategies (COMPASS) trial showed that the combined treatment with rivaroxaban and aspirin reduced the risk of acute limb ischemia, vascular amputation, and mortality, among others when compared to aspirin alone in patients with established vascular diseases [42]. Rivaroxaban and aspirin, however, increased bleeding events relative to aspirin alone although there were no significant effects for severe bleeding [42]. In accordance, Wang et al did not find significant differences in the bleeding events between AP + AC compared with AP alone for infrapopliteal artery diseases [26].

Collectively this data will not conclude changes to the current recommendation following endovascular intervention for PAD due to the lack of evidence to suggest otherwise. However, there was also no enough data to support current recommendations as well for infrapopliteal artery diseases. The combined treatment with AP + AC yielded promising results for the improvement of restenosis without the increase in bleeding events. More studies are warranted to establish the value and superiority of this treatment regime following endovascular intervention.

\section{Antithrombotic treatment for bypass surgery for infrapo- pliteal artery}

It has been reported that the patency rates for autologous distal bypass grafts are superior to those for prosthetic lower extremity bypass grafts [43-45]. Nonetheless, outcomes were comparable between the two groups when appropriate antithrombotic treatment was used following surgery [46]. The routine use of AP therapy for patients with PAD for bypass surgery has been mainly attributed to preserving the patency of the graft [43, 47]. The persistence of high levels of graft occlusion despite the use of MAPT $[14,15]$ has raised the question of modifying the treatment by adding AC or another AP.

Similar to antithrombotic treatment following endovascular therapy, recommendations for treatment following bypass surgery were also variable and without the presence of concrete evidences [35-38, 48]. The ESC guidelines include recommendation of the use of MAPT (aspirin) or DAPT (aspirin and dipyridamole) following bypass surgery (class I recommendations), vitamin $\mathrm{K}$ antagonists after venous infrainguinal bypass surgery, and DAPT (aspirin and clopidogrel) for belowknee prosthetic grafts (class IIb recommendations) [36, 37]. The American College of Chest Physicians recommendation includes the use of MAPT (aspirin or clopidogrel) following bypass surgery (grade 1A), and 1-year treatment with DAPT (aspirin and clopidogrel) for below-knee prosthetic grafts (grade 2C) [37, 38]. The Society for Vascular Surgery practice guidelines recommend the use of MAPT (aspirin or clopidog- rel), or DAPT (aspirin and clopidogrel) for bypass surgery regardless of the graft type (grade 2B) [35, 37].

Clopidogrel, a thienopyridine derivative, has been thought as a strong candidate due to its significant effects on the improvement of cardiac parameters when combined with aspirin [49]. The clopidogrel and acetylsalicylic acid in bypass surgery for peripheral arterial disease (CASPAR) trial [28] showed that the combined effects of aspirin and clopidogrel were only significant over aspirin for graft occlusion and amputation when data were stratified for prosthetic grafts, further underscoring the importance of performing subgroup analysis for the data. Another thienopyridine derivative ticlopidine showed superior results when compared to placebo for graft restenosis and limb amputation [27]. Thus, the addition of thienopyridine derivative to aspirin (DAPT) might improve the outcome following bypass surgery, particularly for prosthetic grafts.

The combined treatment of warfarin and aspirin resulted in significant reduction in prosthetic femoropopliteal bypass graft failure compared to aspirin [50]. In agreement, similar results were reported for venous infrapopliteal bypass graft in high risk group patients [30]. Also, studies for infrapopliteal artery showed the importance of adjusting the levels warfarin to achieve therapeutic INR levels to significantly improve the patency and survival of the prosthetic grafts [34]. The improved survival rates in patients might be attributed to decreased thrombotic heart diseases [30]. Despite the clear advantage of warfarin, its use has been hindered by the reports of high bleeding events by the Dutch Bypass Oral Anticoagulants study [51]. However, increased bleeding events did not include significant increase in major or fatal bleeding, rather most of the bleeding cases were manageable $[30,34]$. This data suggests that ACs, particularly for prosthetic grafts, and the addition of warfarin to MAPT might be prescribed to patient without indicated contraindication and more studies are warranted.

\section{Limitations}

There exists considerable heterogeneity in therapeutic regimen, data reporting, non-consistency in reporting outcomes, especially bleeding. Many of the data was reported in retrospective studies with the known risk of potential bias. The numbers of studies, patients, endovascular or surgical intervention, and follow-up duration included in the treatmentspecific statistical analyses varied across the studies in same treatment groups. Studies that compare DAPT to ACs are not available. Also, many of commonly used APs and ACs are not covered in the literature of infrapopliteal artery diseases. Finally, the review included data from studies published over an extended duration of time (over 10 years); various aspects of these endovascular interventions as well as bypass surgery may have evolved to some extent during this time, thereby affecting outcomes.

\section{Conclusions}

Antithrombotic treatments, especially regimens that combine 
APs and ACs, improve patient outcomes following endovascular intervention and bypass surgery for infrapopliteal artery disease. Further prospective randomized trials with long duration of follow-up are needed to determine the ideal antithrombotic therapy, evaluate the sufficiency of MAPT following endovascular intervention, and to validate the efficacy and safety of the combined AP + AC for this group of patients, particularly high risk patients such as those with history of endovascular intervention or bypass failure.

\section{Acknowledgments}

The authors acknowledge Superior Medical Experts for research and editing assistance.

\section{Financial Disclosure}

None to declare.

\section{Conflict of Interest}

None to declare.

\section{Author Contributions}

AG contributed to the conception and design of the work; AG and $\mathrm{KG}$ contributed to the literature search, data analysis for the work, and drafting the manuscript; MSL, VK and SR critically revised the manuscript.

\section{References}

1. Jakob T, Nordmann AJ, Schandelmaier S, Ferreira-Gonzalez I, Briel M. Fibrates for primary prevention of cardiovascular disease events. Cochrane Database Syst Rev. 2016;11:CD009753.

2. Mahe G, Kaladji A, Le Faucheur A, Jaquinandi V. Internal iliac artery disease management: still absent in the update to TASC II (Inter-Society consensus for the management of peripheral arterial disease). J Endovasc Ther. 2016;23(1):233-234.

3. Rooke TW, Hirsch AT, Misra S, Sidawy AN, Beckman JA, Findeiss L, Golzarian J, et al. Management of patients with peripheral artery disease (compilation of 2005 and 2011 ACCF/AHA Guideline Recommendations): a report of the American College of Cardiology Foundation/American Heart Association Task Force on Practice Guidelines. J Am Coll Cardiol. 2013;61(14):1555-1570.

4. Graziani L, Silvestro A, Bertone V, Manara E, Andreini $\mathrm{R}$, Sigala A, Mingardi R, et al. Vascular involvement in diabetic subjects with ischemic foot ulcer: a new morphologic categorization of disease severity. Eur J Vasc Endovasc Surg. 2007;33(4):453-460.
5. Jones WS, Mi X, Qualls LG, Vemulapalli S, Peterson ED, Patel MR, Curtis LH. Trends in settings for peripheral vascular intervention and the effect of changes in the outpatient prospective payment system. J Am Coll Cardiol. 2015;65(9):920-927.

6. Hong MS, Beck AW, Nelson PR. Emerging national trends in the management and outcomes of lower extremity peripheral arterial disease. Ann Vasc Surg. 2011;25(1):4454.

7. Aboyans V, Criqui MH, Denenberg JO, Knoke JD, Ridker PM, Fronek A. Risk factors for progression of peripheral arterial disease in large and small vessels. Circulation. 2006;113(22):2623-2629.

8. Schillinger M, Haumer M, Schlerka G, Mlekusch W, Exner M, Ahmadi R, Minar E. Restenosis after percutaneous transluminal angioplasty in the femoropopliteal segment: the role of inflammation. J Endovasc Ther. 2001;8(5):477-483.

9. Jamsen T, Manninen H, Tulla H, Matsi P. The final outcome of primary infrainguinal percutaneous transluminal angioplasty in 100 consecutive patients with chronic critical limb ischemia. J Vasc Interv Radiol. 2002;13(5):455463.

10. Schillinger M, Exner M, Mlekusch W, Rumpold H, Ahmadi R, Sabeti S, Haumer M, et al. Vascular inflammation and percutaneous transluminal angioplasty of the femoropopliteal artery: association with restenosis. Radiology. 2002;225(1):21-26.

11. Baumann F, Willenberg T, Do DD, Keo HH, Baumgartner I, Diehm N. Endovascular revascularization of below-the-knee arteries: prospective short-term angiographic and clinical follow-up. J Vasc Interv Radiol. 2011;22(12):1665-1673.

12. Iida O, Soga Y, Kawasaki D, Hirano K, Yamaoka T, Suzuki K, Miyashita Y, et al. Angiographic restenosis and its clinical impact after infrapopliteal angioplasty. Eur J Vasc Endovasc Surg. 2012;44(4):425-431.

13. Norgren L, Hiatt WR, Dormandy JA, Nehler MR, Harris KA, Fowkes FG, TASC II Working Group. Inter-society consensus for the management of peripheral arterial disease (TASC II). J Vasc Surg. 2007;45(Suppl S):S5-67.

14. Mills JL. Mechanisms of vein graft failure: the location, distribution, and characteristics of lesions that predispose to graft failure. Semin Vasc Surg. 1993;6(2):78-91.

15. Brittenden J, Bradbury AW. The durability of iliac and femoral angioplasty. In: The Durability of Vascular and Endovascular Surgery. W B Saunders Company; 1999.

16. Mannava K, Money SR. Current management of peripheral arterial occlusive disease: a review of pharmacologic agents and other interventions. Am J Cardiovasc Drugs. 2007; 7(1):59-66.

17. Iida O, Nanto S, Uematsu M, Morozumi T, Kotani J, Awata $\mathrm{M}$, Onishi T, et al. Cilostazol reduces target lesion revascularization after percutaneous transluminal angioplasty in the femoropopliteal artery. Circ J. 2005;69(10):12561259.

18. The Methods and Applications of Skin Grafting. Hospital (Lond 1886). 1893;14(350):170-172.

19. Laird JR, Schneider PA, Tepe G, Brodmann M, Zeller T, 
Metzger C, Krishnan P, et al. Durability of treatment effect using a drug-coated balloon for femoropopliteal lesions: 24-month results of IN.PACT SFA. J Am Coll Cardiol. 2015;66(21):2329-2338.

20. Li J, Karim A, Shishehbor MH. The use of drug-coated balloons in the treatment of femoropopliteal and infrapopliteal disease. J Cardiovasc Surg (Torino). 2018;59(4):512-525.

21. Nehler MR, Brass EP, Anthony R, Dormandy J, Jiao J, McNamara TO, Hiatt WR, et al. Adjunctive parenteral therapy with lipo-ecraprost, a prostaglandin E1 analog, in patients with critical limb ischemia undergoing distal revascularization does not improve 6-month outcomes. J Vasc Surg. 2007;45(5):953-960; discussion 960-951.

22. Soga Y, Iida O, Kawasaki D, Hirano K, Yamaoka T, Suzuki K. Impact of cilostazol on angiographic restenosis after balloon angioplasty for infrapopliteal artery disease in patients with critical limb ischemia. Eur J Vasc Endovasc Surg. 2012;44(6):577-581.

23. Soga Y, Takahara M, Iida O, Yamauchi Y, Hirano K, Fukunaga M, Zen K, et al. Efficacy of CilostAzol for Below-the-Knee Artery Disease after Balloon AnGioplasty in PatiEnts with Severe Limb Ischemia (CABBAGE Trial). Ann Vasc Surg. 2017;45:22-28.

24. Lejay A, Thaveau F, Aleil B, Geny B, Kretz JG, Stephan D, Chakfe N. Platelet antiaggregation therapy and subinguinal endovascular revascularization. Ann Vasc Surg. 2013;27(5):621-626.

25. Wang J, Zhu YQ, Liu F, Li MH, Zhao JG, Tan HQ, Wang $\mathrm{JB}$, et al. Batroxobin for prevention of restenosis in diabetic patients after infrapopliteal arterial angioplasty: a small randomized pilot trial. Ann Vasc Surg. 2010;24(7):876884.

26. Wang J, Zhu YQ, Li MH, Zhao JG, Tan HQ, Wang JB, Liu F, et al. Batroxobin plus aspirin reduces restenosis after angioplasty for arterial occlusive disease in diabetic patients with lower-limb ischemia. J Vasc Interv Radiol. 2011;22(7):987-994.

27. Becquemin JP. Effect of ticlopidine on the long-term patency of saphenous-vein bypass grafts in the legs. Etude de la Ticlopidine apres Pontage Femoro-Poplite and the Association Universitaire de Recherche en Chirurgie. N Engl J Med. 1997;337(24):1726-1731.

28. Belch JJ, Dormandy J, Committee CW, Biasi GM, Cairols M, Diehm C, Eikelboom B, et al. Results of the randomized, placebo-controlled clopidogrel and acetylsalicylic acid in bypass surgery for peripheral arterial disease (CASPAR) trial. J Vasc Surg. 2010;52(4):825-833, e821822.

29. Clyne CA, Archer TJ, Atuhaire LK, Chant AD, Webster JH. Random control trial of a short course of aspirin and dipyridamole (Persantin) for femorodistal grafts. Br J Surg. 1987;74(4):246-248.

30. Sarac TP, Huber TS, Back MR, Ozaki CK, Carlton LM, Flynn TC, Seeger JM. Warfarin improves the outcome of infrainguinal vein bypass grafting at high risk for failure. J Vasc Surg. 1998;28(3):446-457.

31. Aurshina A, Kibrik P, Eisenberg J, Alsheekh A, Hingorani A, Marks N, Ascher E. Clinical outcomes of direct oral anticoagulants after lower extremity arterial procedures. Vascular. 2018;26(2):189-193.

32. Logason K, Bergqvist D, Study Group on Antothrombotic Prophylaxis of Femorodistal Bypass S. Low molecular weight heparin (enoxaparin) versus dextran in the prevention of early occlusion following arterial bypass surgery distal to the groin. Eur J Vase Endovasc Surg. 2001;21(3):261-265.

33. Samama CM, Gigou F, Ill P. Low-molecular-weight heparin vs. unfractionated heparin in femorodistal reconstructive surgery: a multicenter open randomized study. Enoxart Study Group. Ann Vasc Surg. 1995;9(Suppl):S45-53.

34. LeCroy CJ, Patterson MA, Taylor SM, Westfall AO, Jordan WD, Jr. Effect of warfarin anticoagulation on belowknee polytetrafluoroethylene graft patency. Ann Vasc Surg. 2005;19(2):192-198.

35. Society for Vascular Surgery Lower Extremity Guidelines Writing Group, Conte MS, Pomposelli FB, Clair DG, Geraghty PJ, McKinsey JF, Mills JL, et al. Society for Vascular Surgery practice guidelines for atherosclerotic occlusive disease of the lower extremities: management of asymptomatic disease and claudication. J Vasc Surg. 2015;61(3 Suppl):2S-41S.

36. European Stroke O, Tendera M, Aboyans V, Bartelink ML, Baumgartner I, Clement D, Collet JP, et al. ESC Guidelines on the diagnosis and treatment of peripheral artery diseases: Document covering atherosclerotic disease of extracranial carotid and vertebral, mesenteric, renal, upper and lower extremity arteries: the Task Force on the Diagnosis and Treatment of Peripheral Artery Diseases of the European Society of Cardiology (ESC). Eur Heart J. 2011;32(22):2851-2906.

37. Hess CN, Norgren L, Ansel GM, Capell WH, Fletcher JP, Fowkes FGR, Gottsater A, et al. A structured review of antithrombotic therapy in peripheral artery disease with a focus on revascularization: A TASC (InterSociety Consensus for the Management of Peripheral Artery Disease) initiative. Circulation. 2017;135(25):2534-2555.

38. Alonso-Coello P, Bellmunt S, McGorrian C, Anand SS, Guzman R, Criqui MH, Akl EA, et al. Antithrombotic therapy in peripheral artery disease: Antithrombotic Therapy and Prevention of Thrombosis, 9th ed: American College of Chest Physicians Evidence-Based Clinical Practice Guidelines. Chest. 2012;141(2 Suppl):e669S-e690S.

39. Tomoi Y, Soga Y, Iida O, Fujihara M, Ando K. Impact of cilostazol administration on femoropopliteal in-stent restenosis. J Endovasc Ther. 2017;24(5):640-646.

40. Kostiuk EP. [Ratio of somatostatin-glucagon secretion in diabetes mellitus]. Fiziol Zh. 1985;31(2):195-201.

41. Olinic DM, Tataru DA, Homorodean C, Spinu M, Olinic M. Antithrombotic treatment in peripheral artery disease. Vasa. 2018;47(2):99-108.

42. Eikelboom JW, Connolly SJ, Bosch J, Dagenais GR, Hart RG, Shestakovska O, Diaz R, et al. Rivaroxaban with or without Aspirin in Stable Cardiovascular Disease. N Engl J Med. 2017;377(14):1319-1330.

43. Neale ML, Graham JC, Lane RJ, Cheung DS, Appleberg $M$. The influence of graft type on patency of infrainguinal arterial bypass grafts. J Am Coll Surg. 1994;178(2):155- 
163.

44. Veith FJ, Gupta SK, Ascer E, White-Flores S, Samson RH, Scher LA, Towne JB, et al. Six-year prospective multicenter randomized comparison of autologous saphenous vein and expanded polytetrafluoroethylene grafts in infrainguinal arterial reconstructions. J Vasc Surg. 1986;3(1):104-114.

45. Wixon CL, Mills JL, Westerband A, Hughes JD, Ihnat DM. An economic appraisal of lower extremity bypass graft maintenance. J Vasc Surg. 2000;32(1):1-12.

46. Suckow BD, Kraiss LW, Stone DH, Schanzer A, Bertges DJ, Baril DT, Cronenwett JL, et al. Comparison of graft patency, limb salvage, and antithrombotic therapy between prosthetic and autogenous below-knee bypass for critical limb ischemia. Ann Vasc Surg. 2013;27(8):11341145.

47. Geraghty AJ, Welch K. Antithrombotic agents for preventing thrombosis after infrainguinal arterial bypass surgery. Cochrane Database Syst Rev. 2011;6:CD000536.
48. Brown GP, Iwamoto GK, Monick MM, Hunninghake GW. Cigarette smoking decreases interleukin 1 release by human alveolar macrophages. Am J Physiol. 1989;256(2 Pt 1):C260-264.

49. Chen ZM, Jiang LX, Chen YP, Xie JX, Pan HC, Peto R, Collins R, et al. Addition of clopidogrel to aspirin in 45,852 patients with acute myocardial infarction: randomised placebo-controlled trial. Lancet. 2005;366(9497):16071621.

50. Jackson MR, Johnson WC, Williford WO, Valentine RJ, Clagett GP. The effect of anticoagulation therapy and graft selection on the ischemic consequences of femoropopliteal bypass graft occlusion: results from a multicenter randomized clinical trial. J Vasc Surg. 2002;35(2):292-298.

51. Efficacy of oral anticoagulants compared with aspirin after infrainguinal bypass surgery (The Dutch Bypass Oral Anticoagulants or Aspirin Study): a randomised trial. Lancet. 2000;355(9201):346-351. 